\title{
Mapa Geológico de parte da Folha Arroio América - SH-22-Y-A-IV-1 (MI 2995/1) - Nota explicativa
}

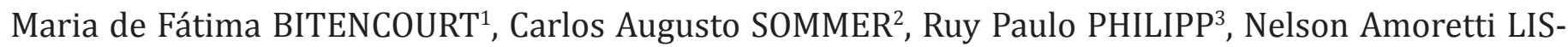 \\ BÔA $^{2}$, André Weissheimer BORBA ${ }^{4}$ \& Norberto DANI ${ }^{2}$
}

1. Departamento de Geologia, Instituto de Geociências, Universidade Federal do Rio Grande do Sul. Caixa Postal 15.001, 91.501-970, Porto Alegre, RS, Brasil. E-mail: fatimab@ufrgs.br.

2. Departamento de Geodésia, Instituto de Geociências, Universidade Federal do Rio Grande do Sul. Caixa Postal 15.001, 91.501-970, Porto Alegre, RS, Brasil. E-mail: casommer@sinos.net, nelsonlisboa@hotmail.com, norberto. dani@ufrgs.br.

3. Departamento de Mineralogia e Petrologia, Instituto de Geociências, Universidade Federal do Rio Grande do Sul. Caixa Postal 15.001, 91.501-970, Porto Alegre, RS, Brasil.E-mail: ruy.philipp@ufrgs.br.

4. Programa de Pós-graduação em Geociências, Universidade Federal do Rio Grande do Sul. Endereço atual: CCNE, Departamento de Geociências ,Universidade Federal de Santa Maria. Av. Roraima, 1000, prédio 17, sala 1131B, Camobi, 97.105-900, Santa Maria, RS, Brasil. E-mail: awborba.geo@gmail.com.

Aceito para publicação em 01/2013.

Versão online publicada em 09/09/2013 (www.pesquisasemgeociencias.ufrgs.br) Mapa disponível em: www.pesquisasemgeociencias.ufrgs.br/4001/8-4001.pdf

\begin{abstract}
Resumo - Esta nota explicativa se refere ao mapa geológico de parte da Folha Arroio América (SH.22-Y-A-IV-1 / MI 2995/1) e tem por base os resultados obtidos durante o Projeto Arroio América, executado em 2003 por professores e alunos do Curso de Geologia da Universidade Federal do Rio Grande do Sul. Diversas unidades litoestratigráficas foram reconhecidas, algumas das quais são inéditas e formalmente designadas. A principal estrutura regional reconhecida é denominada Zona de Cisalhamento Arroio América (ZCAA), composta por diversas zonas miloníticas subverticais de direção NE e cinemática transcorrente esquerda dada por lineação de estiramento de baixo caimento. Significativas reativações de antigos lineamentos em condições rúpteis são encontradas, bem como estruturas rúpteis de direção NW que afetam o embasamento e as rochas sedimentares de idade neoproterozoica a permiana. As sequências de embasamento mais antigas são ortognaisses do Complexo Cambaí, e as rochas supracrustais do Complexo Metamórfico Arroio Marmeleiro (CMAM). Os Dioritos Arroio Branquilho formam uma unidade inédita de biotita-hornblenda dioritos e quartzo-dioritos foliados, que compreendem duas subunidades cogenéticas - a fácies equigranular média e a fácies fina. As relações estruturais observadas indicam que seu posicionamento é anterior à ZCAA. 0 Tonalito Arroio dos Carros (TAC) e os Granitoides Rincão dos Encerrados (GRE) são também unidades inéditas, correlacionadas à Suíte Lagoa da Meia Lua. O TAC compreende hornblenda tonalitos foliados, de granulação média a grossa, e sua foliação magmática grada para uma foliação milonítica devido a seu caráter sintectônico à ZCAA. Os GRE são biotita tonalitos a granodioritos equigranulares finos a médios, tardi-tectônicos em relação à mesma zona de cisalhamento. 0 Granito Passo da Chácara, igualmente inédito, é a unidade granítica mais jovem, compreendendo biotita leucossienogranitos fracamente foliados a maciços. A Formação Maricá é composta por arenitos arcóseo-líticos com intercalação subordinada de conglomerados e folhelhos. Evidências localizadas de condições anquimetamórficas são constatadas, bem como clivagem ardosiana em composições pelíticas. É subdividida em duas fácies, uma resultante de sistema fluvial anastomosado e outra formada em condições marinhas rasas. O Monzonito Tapera, bem como as formações Hilário, Cerro da Pedra e Acampamento Velho, são subunidades do Grupo Bom Jardim. No Monzonito Tapera são reconhecidas quatro fácies com base em características texturais e composicionais: monzonítica plutônica, leucodiorítica plutônica, diorítica plutônica e hipoabissal monzonítica. Nas rochas encaixantes do CMAM, são descritos efeitos de metamorfismo de contato em condições de fácies hornblenda cornubianito. A Formação Hilário compreende derrames andesíticos e diques de andesitos e lamprófiros. A Formação Cerro da Pedra é definida neste trabalho como um pacote de conglomerados formados em sistemas de leques aluviais. A fácies proximal é reconhecida na forma de para- e ortoconglomerados oligomíticos, enquanto a fácies distal é representada por ortoconglomerados polimíticos. A Formação Acampamento Velho é representada por um domo de lava e diques riolíticos associados. A Formação Rio do Sul, de idade permiana, pertencente ao Grupo Itararé, é restrita ao extremo norte da área mapeada, onde ocorrem camadas de arenito fino intercaladas com siltitos.

Palavras-chaves: mapeamento geológico, Escudo Sul-rio-grandense, granitoides neoproterozoicos, rochas sedimentares neoproterozoicas, rochas vulcânicas neoproterozoicas, rochas sedimentares permianas.
\end{abstract}

\footnotetext{
Abstract - GEOlOGiCAL MAP OF PART OF THE ARROIO AMÉRICA SHEET - SH-22-Y-A-IV-1 (MI 2995/1) - EXPLANATORY NOTE. This explanatory note refers to the geological map of part of the Arroio América Sheet (SH.22-Y-AIV-1 / MI 2995/1) and is based on the results obtained during the Arroio América Project, carried out in 2003
} 
by professors and undergraduate students of the Geology Course, Federal University of Rio Grande do Sul. Seve ral lithostratigraphic units were recognized, some of which are newly-defined and formally named. The main large-scale structure recognized and named is the Arroio América Shear Zone (ZCAA), composed of several NE-trending, subvertical mylonitic zones of sinistral transcurrent kinematics given by shallow-plunging stretching lineation. Brittle reactivations of old trends are significant, as well as NW-trending brittle structures which affect basement and sedimentary rocks from Neoproterozoic to Permian age. The oldest basement sequences are orthogneisses of the Cambaí Complex, and supracrustal rocks of the Arroio Marmeleiro Metamorphic Complex (CMAM). The Arroio Branquilho Diorites form a newly-defined unit of foliated biotite-hornblende diorites and quartz-diorites and comprise two co-genetic subunits - the medium-grained equigranular facies, and the fine-grained facies. Structural relations indicate that their emplacement predates the ZCAA. The Arroio dos Carros Tonalites (TAC) and Rincão dos Encerrados Granitoids (GRE) are also newly-defined units, correlated to the Lagoa da Meia Lua Suite. The TAC comprises medium- to coarse-grained, foliated hornblende tonalites, and their magmatic flow foliation grades into a mylonitic one due to its syntectonic character relative to the ZCAA. The GRE are equigranular, fine to medium-grained biotite tonalites to granodiorites which are late-tectonic relative to the same shear zone. The Passo da Chácara Granite, also newly-defined, is the youngest granitic unit, and comprises weakly-foliated to massive biotite leucosyenogranites. The Maricá Formation is composed of lithic arkosean sandstones with subordinate interleaving of shale and conglomerates. Local evidences of anchimetamorphic conditions and slaty cleavage in pelitic compositions are found. Two facies units are described, the first resulting from a braided river system and the second formed in shallow marine conditions. The Tapera Monzonite, as well as Hilário, Cerro da Pedra and Acampamento Velho formations are sub-units of the Bom Jardim Group. In the Tapera Monzonite, four different facies are recognized, based on compositional and textural characteristics: monzonitic plutonic, leucodioritic plutonic, dioritic plutonic and hypoabyssal monzonitic facies. In the enclosing CMAM rocks, contact metamorphism of hornblende-hornfels conditions is described. The Hilário Formation comprises andesitic flows, as well as andesitic and lamprophyric dikes. The Cerro da Pedra Formation is presently defined to describe conglomerate packs formed in alluvial-fan systems. A proximal facies is recognized as oligomitic para- and orthoconglomerates, while a distal facies is represented by polimitic orthoconglomerates. The Acampamento Velho Formation is represented by a rhyolitic lava-dome and related dikes. The Permian Rio do Sul Formation, belonging to the Itararé Group, is restricted to the northern extreme of the mapped area, where fine-grained sandstone layers are interleaved with siltstones.

Keywords: geological mapping, Sul-rio-grandense Shield, Neoproterozoic granitoids, Neoproterozoic sedimentary rocks, Neoperoterozoic volcanic rocks, Permian sedimentary rocks.

\section{Introdução}

Esta nota explicativa disponibiliza uma síntese dos resultados obtidos durante o mapeamento geológico de parte da Folha Arroio América (SH.22-Y-A-IV-1 / MI 2995/1). Tem por base o trabalho realizado por estudantes e professores do Curso de Geologia da Universidade Federal do Rio Grande do Sul, como parte do Projeto Arroio América, desenvolvido em 2003 com financiamento do Instituto de Geociências da UFRGS.

Os trabalhos envolveram uma etapa de confecção de mapa fotogeológico preliminar, com base na interpretação de fotografias aéreas em escala 1:60.000 e 1:25.000, seguida de 17 dias de campo e estudos petrográficos distribuídos em dois semestres letivos. A versão integral do Projeto Arroio América (UFRGS, 2003), incluindo volume de textos, mapa geológico e mapa de amostragem, ambos em escala 1:25.000, está disponível para consulta na biblioteca do Instituto de Geociências da UFRGS.

A nomenclatura estratigráfica empregada para as litologias de embasamento tem por base as recomendações da International Subcommission on Stratigraphic Classification - International Union of Geological Sciences (ISSC-IUGS, 1994), entendendo-se como unidades litoestratigráficas “...corpos de rochas, acamadados ou não, definidos e caracterizados com base em suas propriedades litológicas e em suas relações estratigráficas". São também aplicados neste trabalho os princípios discutidos por White et al. (2001), Philipp et al. (2003) e Bitencourt et al. (2004) no que se refere ao emprego dos termos Suíte e Fácies para rochas ígneas.

As rochas plutônicas são individualizadas utilizando-se um conjunto de critérios que abrangem suas características texturais, mineralógicas, estruturais e composicionais, além de relações de intrusão/inclusão determinadas com base em dados de campo, seguidos de estudo petrográfico e microestrutural.

\section{Unidades litoestratigráficas e relações estruturais}

Na área mapeada são reconhecidos cinco grandes conjuntos de novas unidades litoestratigráficas, aqui denominadas formalmente: os Dioritos Arroio Branquilho, o Tonalito Arroio dos Carros, os Granitoides Rincão dos Encerrados, o Granito Passo da Chácara e a Formação Cerro da Pedra. Em unidades previamente definidas, como o Monzonito Tapera, são individualizadas fácies composicionais passíveis de representação na escala proposta. Sendo este o primeiro mapa em escala de semi-detalhe realizado na Folha Arroio América, uma fração significativa das unidades de embasamento consta em mapas anteriores como parte da unidade Cambaí (Formação, Grupo ou Complexo). 
No quadro 1, são apresentadas as localizações geográficas das seções-tipo das unidades litoestratigráficas definidas neste trabalho, bem como as localizações das melhores exposições, na área de estudo, de unidades previamente definidas. Portanto, as unidades que se caracterizam por exposições geralmente pobres como os complexos Cambaí e Arroio Marmeleiro, não estão indicadas.

\begin{tabular}{|c|c|c|}
\hline \multicolumn{2}{|c|}{ Unidade / Subunidade } & Coordenadas UTM (m) \\
\hline \multicolumn{2}{|l|}{ Formação Rio do Sul } & $6.613 .799 \mathrm{~N} / 224.203 \mathrm{E}$ \\
\hline \multicolumn{2}{|l|}{ Formação Acampamento Velho } & $6.611 .813 \mathrm{~N} / 223.510 \mathrm{E}$ \\
\hline \multicolumn{2}{|c|}{ Formação Cerro da Pedra (fácies proximal e fácies distal) * } & $6.606 .000 \mathrm{~N} / 230.000 \mathrm{E}$ \\
\hline \multirow{3}{*}{ Monzonito Tapera } & $\begin{array}{c}\text { fácies plutônica } \\
\text { diorítica * }\end{array}$ & $6.596 .946 \mathrm{~N} / 221.125 \mathrm{E}$ \\
\hline & $\begin{array}{l}\text { fácies plutônica } \\
\text { leucodiorítica* }\end{array}$ & $6.597 .252 \mathrm{~N} / 221.649 \mathrm{E}$ \\
\hline & $\begin{array}{l}\text { fácies plutônica } \\
\text { monzonítica * }\end{array}$ & $6.595 .272 \mathrm{~N} / 224.094 \mathrm{E}$ \\
\hline \multicolumn{2}{|l|}{ Formação Maricá } & $6.605 .137 \mathrm{~N} / 227.613 \mathrm{E}$ \\
\hline \multicolumn{2}{|l|}{ Granito Passo da Chácara * } & $6.610 .122 \mathrm{~N} / 220.254 \mathrm{E}$ \\
\hline \multicolumn{2}{|c|}{ Granitoides Rincão dos Encerrados * } & $6.604 .648 \mathrm{~N} / 222.577 \mathrm{E}$ \\
\hline \multicolumn{2}{|l|}{ Tonalito Arroio dos Carros * } & $6.604 .600 \mathrm{~N} / 224.786 \mathrm{E}$ \\
\hline \multirow{4}{*}{ Dioritos Arroio Branquilho * } & $\begin{array}{c}\text { fácies equigranular média } \\
\text { indeformada }\end{array}$ & $6.607 .748 \mathrm{~N} / 216.724 \mathrm{E}$ \\
\hline & $\begin{array}{l}\text { fácies equigranular média } \\
\text { milonítica }\end{array}$ & $6.598 .842 \mathrm{~N} / 223.237 \mathrm{E}$ \\
\hline & $\begin{array}{c}\text { fácies equigranular fina } \\
\text { indeformada }\end{array}$ & $6.605 .295 \mathrm{~N} / 218.639 \mathrm{E}$ \\
\hline & $\begin{array}{c}\text { fácies equigranular fina } \\
\text { milonítica }\end{array}$ & $6.600 .530 \mathrm{~N} / 223.455 \mathrm{E}$ \\
\hline
\end{tabular}

Quadro 1. Localização das seções-tipo das unidades definidas neste trabalho $\left({ }^{*}\right)$ e melhores exposições, na área de estudo, das unidades previamente definidas.

A principal estrutura reconhecida e denominada é a Zona de Cisalhamento Arroio América (ZCAA), que compreende um conjunto de zonas miloníticas discretas, ramificadas, de cinemática transcorrente esquerda, com espessura de centenas de metros. A foliação milonítica tem direção NE e alto ângulo de mergulho, contendo lineação de estiramento de baixo a médio caimento para NE ou SW (Fig. 1A). 0 sentido de movimento é dado por porfiroclastos assimétricos de plagioclásio e hornblenda, subordinadamente por shear bands de direção NNE.

As estruturas formadas em regime dúctil da ZCAA, sob condições de temperatura compatíveis com as da fácies xistos verdes superior a anfibolito, são retomadas em nível crustal raso, gerando-se zonas de cataclase concordantes ou subconcordantes, onde os miloni- tos têm sua estrutura principal obliterada pela intensa quebra dos grãos, por vezes acompanhada de hidrotermalismo. 0 sentido de movimento durante esta reativação é também esquerdo, com significativa componente oblíqua, resultando em lineação de estiramento com caimento de até $30^{\circ}$ para NE.

Estruturas rúpteis de direção NW e alto ângulo de mergulho são também expressivas na Folha Arroio América, deslocando as estruturas dúcteis e dúcteis-rúpteis com sentido de movimento esquerdo e componente oblíqua que gera abatimento do bloco norte na zona de falha principal, porção centro-oeste da Folha. Diversas reativações de ambos os sistemas são observadas, afetando as sequências sedimentares neoproterozóicas e gondwânicas. 
(A)

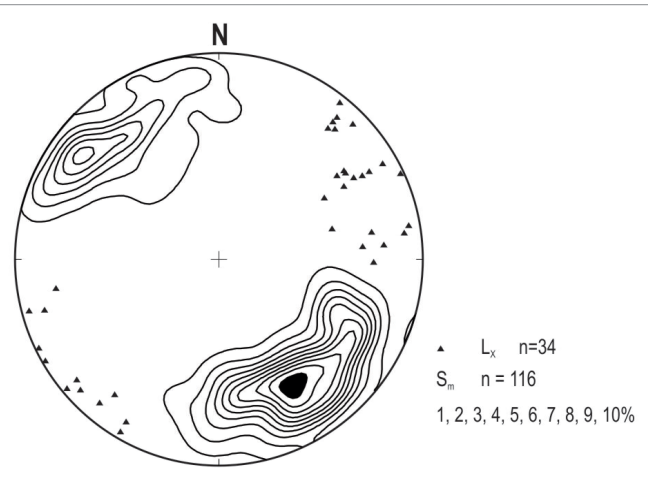

(B)

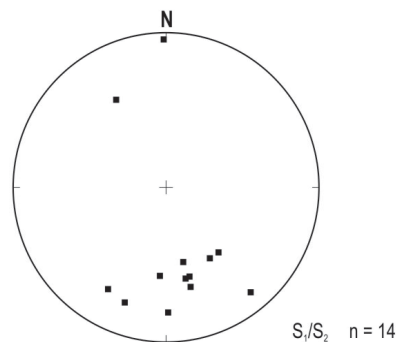

(D)

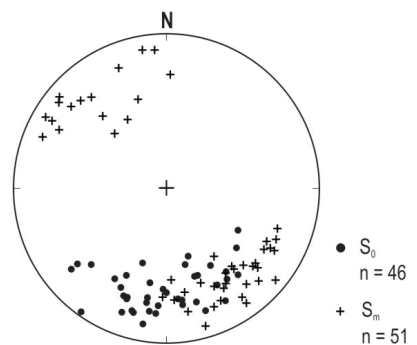

(F)

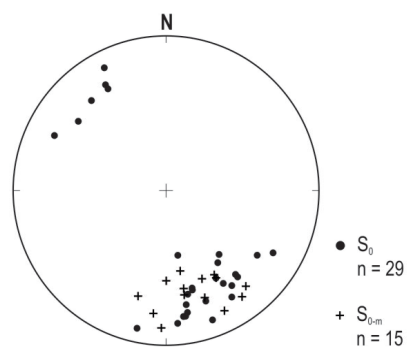

(C)

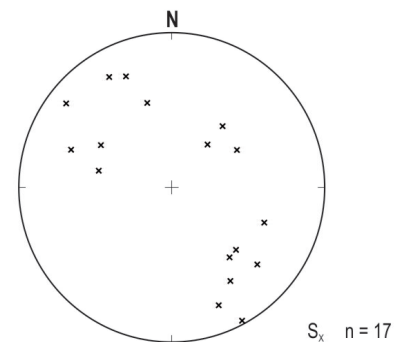

(E)

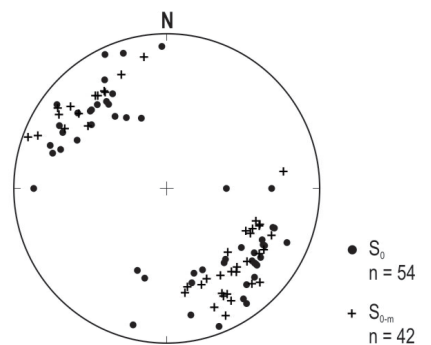

(G)

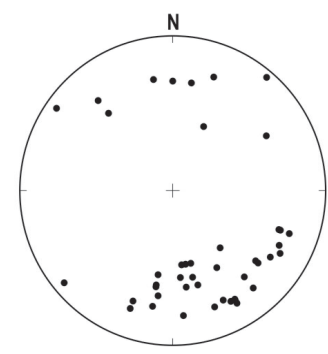

Figura 1. Estruturas planares e lineares das unidades de embasamento representadas em rede equiárea de Schmidt (hemisfério inferior); S0.- foliação magmática, S0-m - foliação composta, magmático-deformacional, Sm - foliação milonítica,. S1/S2 - foliação metamórfica, SX - xistosidade, LX - lineação de estiramento: (A) diagrama de contornos para polos dos planos de foliação milonítica relacionada à Zona de Cisalhamento Arroio América e orientação da lineação de estiramento em todas as unidades; (B) polos dos planos de foliações metamórficas nos ortognaisses do Complexo Cambaí; (C) polos dos planos de xistosidade do Complexo Metamórfico Arroio Marmeleiro; (D) polos dos planos de foliação primária e de foliação milonítica nos Dioritos Arroio Branquilho; (E) polos dos planos de foliação magmática e foliação composta no Tonalito Arroio dos Carros; (F) polos dos planos de foliação magmática e foliação composta nos Granitoides Rincão dos Encerrados; (G) polos dos planos de foliação magmática no Granito Passo da Chácara.

\subsection{Complexo Cambaí (CC)}

As rochas desta unidade têm ocorrência restrita, na forma de lajeados e blocos com alto grau de alteração intempérica. Constituem principalmente gnaisses tonalítico-trondhjemíticos e dioríticos, correlacionáveis aos Gnaisses Cambaí (Porcher, 2000) e a parte dos tipos litológicos descritos na Suíte Ortometamórfica Imbicuí de Kraemer (1995). Uma vez que o nível de exposição destas rochas é muito pobre na área mapeada, optou-se por empregar a denominação de hierarquia mais alta, conforme discutido por Bitencourt et al. (2004), tendo-se em mente a possibilidade de um futuro mapeamento de áreas adjacentes permitir sua designação estratigráfica mais precisa.

$\mathrm{Na}$ área da Folha Arroio América, os gnaisses são interpretados como septos do embasamento no interior dos dioritos, tonalitos e granitos mapeados. No seu limite norte, o contato com os Granitoides Rincão dos Encerrados é tectônico, marcado pelas estruturas transcorrentes da ZCAA e suas reativações. Ao sul, o contato com o Tonalito Arroio dos Carros é inferido, e a leste a unidade é recoberta pelas rochas sedimentares da Formação Maricá.

Os ortognaisses apresentam bandamento composto, caracterizado pela intercalação de corpos tabulares 
de composição diorítica e tonalítica e, internamente aos mesmos, por níveis máficos e félsicos irregulares e pouco definidos. Os níveis máficos têm espessura milimétrica, são ricos em biotita e/ou hornblenda, com textura lepidoblástica e nematoblástica fina a média. Os níveis félsicos têm espessura centimétrica, composição quartzo-feldspática e textura granoblástica inequigranular interlobada fina a média. As associações minerais em equilíbrio, como plagioclásio, biotita e hornblenda, indicam condições metamórficas compatíveis com as da fácies anfibolito inferior a médio do metamorfismo regional orogênico. 0 bandamento metamórfico está deformado, sendo identificadas com frequência dobras isoclinais intrafoliais com e sem raiz, de amplitude centimétrica a métrica, sugerindo o desenvolvimento de duas foliações metamórficas principais, $S_{1}$ e $S_{2}$ (Fig. 1B). São registradas, ainda, dobras abertas, de amplitude métrica a decamétrica, com planos axiais subverticais, de direção 300 a 330E e eixos inclinados de 10 a $15 \mathrm{E}$ para NW.

Além da deformação relacionada ao metamorfismo regional, esta unidade é afetada pela ZCAA. Nas zonas de alta deformação, a distinção entre as fases composicionais é dificultada pelo estiramento e paralelismo dos corpos, pela falta de boas exposições e pelo alto grau de alteração intempérica das rochas.

\subsection{Complexo Metamórfico Arroio Marmeleiro (CMAM)}

Esta unidade foi inicialmente caracterizada por Kraemer (1995) como uma sequência supracrustal constituída por xistos aluminosos e magnesianos, quartzitos, lentes de mármore e corpos de serpentinitos intercalados. Posteriormente Porcher (2000) redefiniu esta associação como Sequência Metamórfica Arroio Marmeleiro, composta de metapelitos, quartzitos, mármores, rochas calci-silicáticas, grafita xistos, xistos magnesianos e paranfibolitos. 0 contato tectônico entre estas unidades, por meio de uma zona de thrusting, é referido por Fernandes \& Porcher (2000). Na área de estudo não foram observadas relações com os ortognaisses do Complexo Cambaí.

As rochas deste complexo estão restritas ao extremo sudoeste da área mapeada, onde foram identificados xistos quartzo-feldspáticos, pelíticos e calci-silicáticos, bem como rochas cornubianíticas relacionadas à intrusão do Monzonito Tapera.

A estrutura xistosa é pouco desenvolvida, subparalela ao acamamento reliquiar marcado por variação composicional e de tamanho de grão em níveis ricos em quartzo. A xistosidade tem direção predominantemente NE, com mergulho variável para NW e SE, e a disposição de seus pólos (Fig. 1C) sugere a presença de dobras em grande escala, com superfície axial subvertical de direção NE. Sobreposta à xistosidade ocorre foliação milonítica com direção NE e disposição subvertical. A reativação cataclástica da zona de cisalhamento gera um forte fraturamento e, de maneira localizada, a formação de cataclasitos.

Nas imediações do contato com o Monzonito Tapera, as litologias do CMAM adquirem estrutura maciça ou fracamente foliada, localizadamente mostrando acamadamento reliquiar marcado por níveis de espessura milimétrica a centimétrica, onde quartzo e feldspatos de textura granoblástica poligonal fina e cristais aciculares de hornblenda caracterizam o metamorfismo de contato.

\subsection{Dioritos Arroio Branquilho (DAB)}

O termo Dioritos Arroio Branquilho é proposto para designar rochas de composição diorítica a quartzo-diorítica, com foliação primária dada pelo alinhamento dimensional de plagioclásio e minerais máficos, e foliação milonítica superposta em zonas de cisalhamento. A designação se refere às áreas adjacentes ao arroio de mesmo nome, onde ocorrem suas melhores exposições (Quadro 1).

Duas fácies texturais cogenéticas são identificadas, cujas relações de intrusão mútua são observadas em porções pouco afetadas pelas zonas de cisalhamento. A fácies equigranular média (fem) compreende biotita-hornblenda dioritos a quartzo-dioritos mesocráticos, com rara ocorrência de termos mais ricos em quartzo. A textura é equigranular média a grossa, com os minerais máficos formando agregados intersticiais. A fácies equigranular fina (fef) é formada por hornblenda-dioritos melanocráticos, com biotita subordinada, textural e composicionalmente homogêneos. Alanita e titanita são os acessórios característicos de ambas as variedades dos DAB. Em ambas as fácies, observa-se a ocorrência localizada de estratificação modal, caracterizada pela alternância de estratos de espessura centimétrica de hornblenditos, dioritos e leucodioritos.

$\mathrm{Na}$ borda nordeste do corpo diorítico, extremo norte da área mapeada, observa-se uma gradação localizada para rochas de composição tonalítica, em geral leucocráticas e raramente mesocráticas, com significativa variação textural, ocasionalmente apresentando bandamento e dobras de fluxo magmático.

Na porção oeste da área, a foliação de fluxo dos Dioritos Arroio Branquilho tem direção NW a WNW, com médio ângulo de mergulho para NNE, tendendo a adquirir direção NE e alto ângulo de mergulho quando afetada pela foliação milonítica da ZCAA (Fig. 1D).

Os contatos com as rochas do CMAM são encobertos. A ausência de bandamento metamórfico, bem como o truncamento da trama magmática pela trama milonítica relacionada à ZCAA, são os critérios utilizados para justificar o posicionamento estratigráfico dos Dioritos Arroio Branquilho como posteriores aos complexos Cambaí e Arroio Marmeleiro e pré-tectônicos em relação à movimentação principal da ZCAA. 


\subsection{Suíte Lagoa da Meia Lua}

\section{Tonalito Arroio dos Carros (TAC)}

Esta unidade compreende as rochas tonalíticas ocorrentes na região centro-norte da Folha Arroio América, e suas melhores exposições são encontradas em áreas adjacentes ao arroio homônimo (Quadro 1), na forma de matacões e extensos lajeados.

O Tonalito Arroio dos Carros é um hornblenda tonalito foliado, de textura equigranular hipidiomórfica média a grossa, textural e composicionalmente homogêneo. Contém alanita e titanita como acessórios principais, e minerais máficos bem formados, geralmente em agregados. Ocasionalmente são observados xenólitos de dimensões centimétricas de ortognaisses, dioritos equigranulares médios, dioritos melanocráticos finos, hornblenditos e xistos máficos. Foliação e lineação primárias são bem desenvolvidas, marcadas pelo alinhamento dimensional de hornblenda euédrica, e gradam para estrutura milonítica de mesma orientação, com lineação de estiramento marcada por quartzo fitado e agregados máficos lenticulares. Tanto a foliação de fluxo $\left(\mathrm{S}_{0}\right)$ como a foliação milonítica $\left(\mathrm{S}_{0-\mathrm{m}}\right)$ têm direção NE e alto ângulo de mergulho para NW ou SE (Fig. 1E).

Os termos mais fortemente deformados contêm porfiroclastos muito estirados de hornblenda, com cauda de actinolita neoformada, bem como textura granoblástica interlobada em plagioclásio, sugestiva de deformação em condições de temperatura compatíveis com as da fácies anfibolito. De modo localizado, desenvolvem-se shear bands de direção NS, corroborando o sentido de movimento esquerdo indicado por caudas assimétricas de porfiroclastos de plagioclásio e hornblenda.

0 Tonalito Arroio dos Carros tem contato encoberto (inferido) com os ortognaisses do Complexo Cambaí, sendo interpretado como intrusivo nesta unidade devido à presença de xenólitos da mesma. Relações de campo demonstram seu caráter intrusivo nos Dioritos Arroio Branquilho, principalmente na porção sul da área de estudo, onde se encontram apófises de espessura métrica dos primeiros nos últimos. A concordância observada entre suas estruturas primária e milonítica (Fig. 1E), bem como o caráter progressivamente mais acentuado da componente de estado sólido próximo às bordas, indicam sua condição sintectônica em relação à movimentação principal da ZCAA.

As características composicionais e o posicionamento tectono-estratigráfico do Tonalito Arroio dos Carros sugerem que o mesmo faz parte da Suíte Lagoa da Meia Lua, conforme definida por UFRGS (1997).

\section{Granitoides Rincão dos Encerrados (GRE)}

Sob esta denominação são reunidos biotita tonalitos e granodioritos que ocorrem na porção noroeste da área, nos arredores da localidade de Rincão dos Encerrados. Estes granitoides afloram predominantemente na forma de blocos e matacões, raramente em lajeados, e as melhores exposições são encontradas nos arredores da localidade homônima (Quadro 1).

A unidade compreende biotita tonalitos a granodioritos foliados, de textura equigranular hipidiomórfica fina a média. É característica a ocorrência de biotita de forma disseminada e homogênea, raramente acompanhada de hornblenda. Cristais ovoides de plagioclásio esparsos, com até $1,5 \mathrm{~cm}$ de comprimento, são esporádicos. Titanita é o acessório principal, ocorrendo tipicamente como cristais euédricos da ordem de $1 \mathrm{~mm}$ de tamanho. De modo localizado, observam-se concentrações de enclaves microgranulares máficos alongados que atingem no máximo $20 \mathrm{~cm}$ de comprimento.

A foliação de fluxo é marcada pela orientação dimensional de lamelas de biotita, e seu grau de desenvolvimento é variável, ocorrendo desde termos com foliação incipiente ou isótropos até termos fortemente foliados. Apenas localizadamente se observa foliação milonítica, na porção centro-norte da área, onde a reativação das estruturas da ZCAA é responsável pelo contato desta unidade com os ortognaisses do Complexo Cambaí. A foliação primária tem direção NE a ENE com médio a alto ângulo de mergulho, predominantemente para NW (Fig. 1F).

Os granitoides desta unidade contêm diversos xenólitos de ortognaisses, de dimensões centimétricas a métricas, bem como fragmentos das variedades petrográficas dos Dioritos Arroio Branquilho. 0 contato com o Tonalito Arroio dos Carros é encoberto ou tectônico, dificultando o estabelecimento de sua posição estratigráfica. Relações diretas de intrusão entre estas unidades não foram observadas em campo, e a similaridade composicional das mesmas torna improvável a preservação de xenólitos. Evidências indiretas justificam o posicionamento estratigráfico adotado, tais como: (i) no bloco abatido, delimitado por falhas de direção NW, porção centro-oeste da área mapeada, observa-se um discreto afinamento do tamanho de grão dos GRE contra o TAC, sugestivo de que o primeiro é mais jovem; (ii) seu caráter mais potássico, relativo ao TAC, seria compatível com um magmatismo mais evoluído; (iii) o menor grau de desenvolvimento da foliação magmática, e principalmente da componente de deformação de estado sólido a ela associada, sugere também o caráter mais tardio dos GRE em relação ao TAC.

As características composicionais e texturais dos Granitoides Rincão dos Encerrados, bem como seu posicionamento tectônico e estratigráfico, levaram UFRGS (2003) a correlacioná-los ao Tonalito Buriti descrito por UFRGS (2001) na região de Vila Nova, a noroeste da área mapeada.

\subsection{Granito Passo da Chácara (GPC)}

O Granito Passo da Chácara é definido neste traba- 
lho e compreende biotita leucossienogranitos de coloração avermelhada, textura hipidiomórfica equigranular média, com quartzo caracteristicamente abundante, facetado ou intersticial. Na maior parte da área mapeada, os leucogranitos têm foliação primária marcada pelo alinhamento de lamelas de biotita e de agregados alongados, compostos por grãos equidimensionais de quartzo e feldspatos. O grau de desenvolvimento da foliação é variável, observando-se também termos isótropos, embora subordinados. Em raros locais, sobretudo no extremo norte da área mapeada, uma componente de deformação de estado sólido é constatada nas litologias do GPC, gerando lineação de estiramento no quartzo.

As rochas desta unidade são textural e composicionalmente monótonas e afloram principalmente como matacões, raramente em lajeados, sendo as melhores exposições encontradas na porção noroeste da área mapeada (Quadro 1).

A área correspondente ao GPC coincide em parte com a do Granito Macedo, referido por Porcher (2000: p. 26), que remete a cartografia original do mesmo a trabalhos de graduação do Instituto de Geociências (UFRGS, 1966, apud Porcher 2000). 0 Granito Macedo é descrito como um corpo de sienogranito equigranular médio, contendo K-feldspato micropertítico, associado a rochas riolíticas e intrusivo na Formação Maricá, sendo então correlacionado à Suíte Intrusiva Saibro de Nardi \& Bonin (1991). No presente trabalho, a denominação não é mantida, uma vez que não é constatada a associação destas rochas com riolitos, e o fato de apresentarem intrusões riolíticas discordantes de sua foliação atesta que são mais antigas. Além disso, não são observadas evidências diretas ou indiretas do caráter intrusivo do GPC nas litologias da Formação Maricá, que se sobrepõem a ele discordantemente de sua foliação.

Os GPC apresentam estreita margem resfriada contra os Dioritos Arroio Branquilho e Granitoides Rincão dos Encerrados, caracterizada pelo afinamento de seu tamanho de grão e desenvolvimento de textura porfirítica de matriz fina em distâncias métricas. A ocorrência frequente de veios e apófises de espessura centimétrica a métrica do GPC no Complexo Cambaí, Dioritos Arroio Branquilho, Tonalito Arroio dos Carros e Granitoides Rincão dos Encerrados, bem como a presença de xenólitos de dimensões centimétricas a métricas dos primeiros, constituem evidências adicionais de seu posicionamento estratigráfico. Veios aplíticos e pegmatíticos são localizadamente significativos em volume, intrusivos nos granitoides mais antigos e no próprio leucogranito, com o qual mostram contatos difusos.

A foliação de fluxo magmático tem direção NE a ENE, com mergulho de médio a alto ângulo para NW ou SE (Fig. 1G). A virtual ausência de componente de deformação de estado sólido na foliação magmática do GPC, bem como seu contato intrusivo e discordante nos termos miloníticos da borda do Tonalito Arroio dos Carros, extremo oeste da área de estudo, sugerem que seu posicionamento é tardio em relação à movimentação principal da ZCAA. Por outro lado, a ocorrência de lineação de estiramento restrita ao quartzo, observada no extremo nordeste da área, sugere que o GPC foi afetado pela principal reativação da ZCAA.

\subsection{Formação Maricá (FM)}

A Formação Maricá (FM), definida por Leinz et al. (1941) e revisada por Ribeiro (1983), compreende arenitos arcoseanos, siltitos, folhelhos e conglomerados subordinados. As porções conglomeráticas possuem seixos e blocos bem arredondados de rochas metamórficas, granitos, rochas sedimentares e, raramente, quartzo. Os trabalhos de Paim (1994) e Paim et al. (1995), sintetizados na revisão apresentada por Paim et al. (2000), focalizam a bacia sob o ponto de vista paleogeográfico, com base no reconhecimento de discordâncias e na aplicação da aloestratigrafia. A partir desta abordagem, a Formação Maricá foi redefinida como Alogrupo Maricá, limitado na base por discordância angular com rochas metamórficas e no topo por discordância angular com rochas vulcânicas e sedimentares dos alogrupos Bom Jardim e Cerro do Bugio.

Na área do presente trabalho, a Formação Maricá é composta por pacotes de arenitos arcósio-líticos com intercalação subordinada de folhelhos e conglomerados, apresentando evidências localizadas de metamorfismo de soterramento, metamorfismo de contato e clivagem ardosiana nos termos pelíticos. É subdividida em duas unidades de fácies distintas, uma fluvial (unidade de fácies 1) e uma marinha (unidade de fácies 2), somente para efeito de descrição, uma vez que as mesmas não são separáveis na escala de mapeamento. A localização de suas melhores exposições é indicada no quadro 1.

A unidade de fácies 1 é composta por camadas tabulares ou lenticulares de arenitos médios a grossos, mal selecionados, com estratificação cruzada acanalada ou plano-paralela, ocorrendo seixos de granitos, milonitos, quartzo leitoso, vulcanitos e metamorfitos, dispersos ou concentrados em níveis centimétricos. Frequentemente possui intercalações de níveis lenticulares centimétricos a métricos de ortoconglomerados polimíticos, com raras intercalações de camadas centimétricas a métricas de pelitos com estratificação plano-paralela. Esta unidade é interpretada como um sistema fluvial entrelaçado, com paleocorrentes para E-SE.

A unidade de fácies 2 , representada por camadas tabulares ou lenticulares de 1 a 1,5 m de espessura de arenitos finos intercalados com folhelhos, com laminação plano-paralela e estratificação swash e flaser, é interpretada como parte de um sistema marinho raso.

As litologias da Formação Maricá são afetadas de modo significativo pela tectônica rúptil. São raramen- 
te encontradas em posição suborizontal, observando-se basculamento de seus pacotes de até 80ํㅡ. (Fig. $2 \mathrm{~A} \mathrm{e}$ 2B), embora com predominância de valores da ordem de 30-40 para NE e SE. A norte da estrutura de direção NE que baliza as litologias da Formação Cerro da Pedra, os pacotes sedimentares da Formação Maricá mergulham preferencialmente para NE (Fig. 2A). A sul da mesma estrutura, valores similares de mergulho são encontrados, preferencialmente para SE (Fig. 2B).
Nesta região, os valores de mergulho atingem $60^{\circ}$ nas proximidades do Monzonito Tapera.

\subsection{Grupo Bom Jardim}

O Grupo Bom Jardim foi definido originalmente por Ribeiro et al. (1966) e modificado por Ribeiro \& Fantinel (1978). Esta designação é aqui empregada

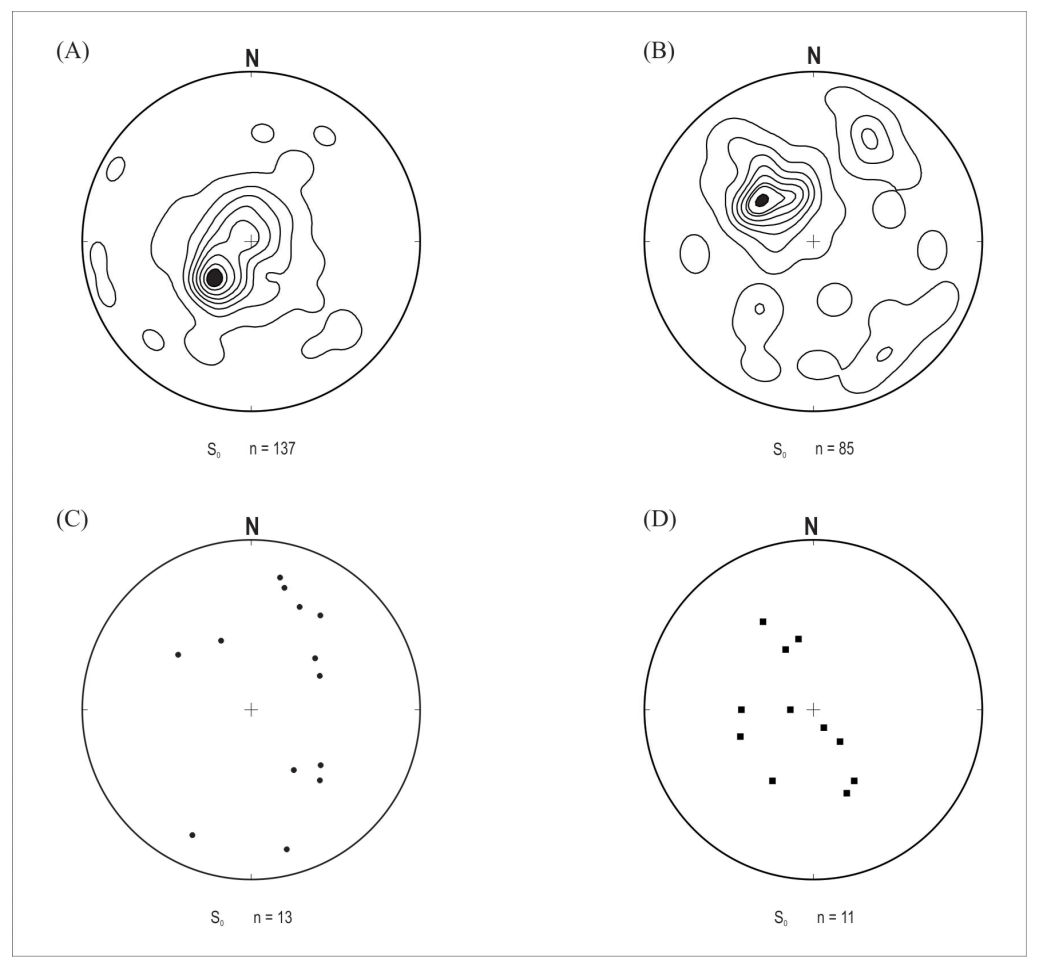

Figura 2. Diagramas de contornos para polos de acamadamento dos pacotes sedimentares da Formação Maricá a norte (A) e a sul (B) da falha de direção NE que baliza a Formação Cerro da Pedra. Rede equiárea de Schmidt, hemisfério inferior; contornos em 1, 3, 5, 7, 9 11, 13, 15\%; (C) polos de planos de foliação de fluxo do Monzonito Tapera; (D) polos de planos de acamadamento da Formação Cerro da Pedra.

para agrupar as rochas vulcânicas e hipabissais andesíticas da Formação Hilário e os riolitos da Formação Acampamento Velho. A unidade Monzonito Tapera é inserida neste grupo por ser correlacionável ao magmatismo da Formação Hilário. A inclusão da Formação Cerro da Pedra, definida neste trabalho, no Grupo Bom Jardim, decorre de suas relações estratigráficas com as rochas das formações Hilário e Acampamento Velho.

\section{Monzonito Tapera (MT)}

Os litotipos desta unidade foram originalmente descritos e reunidos por Matos Neto et al. (1980) em um complexo quartzo-monzonítico-riodacítico relacionado ao magmatismo da Formação Acampamento Velho. Posteriormente, Lima \& Nardi (1992) identificaram nesta unidade monzonitos epizonais, leucodioritos, diques monzoníticos e traquiandesíticos, que foram estratigraficamente relacionados, a partir de critérios litoquímicos e de campo, ao magmatismo da Formação Hilário, vinculado à Associação Shoshonítica de Lavras do Sul (Nardi \& Lima, 1985). O termo Mon- zonito Tapera foi definido por Gastal et al. (2006) para reunir as intrusões monzoníticas que ocorrem ao norte do Complexo Granítico de Lavras (Nardi, 1984). Dados geocronológicos obtidos pelo método ${ }^{207} \mathrm{~Pb} /{ }^{206} \mathrm{~Pb}$, por evaporação de zircão, indicam idades ao redor de 601599 Ma para as rochas monzoníticas e quartzo-monzoníticas desta unidade (Gastal et al., 2005).

No presente trabalho, esta designação é utilizada para descrever rochas de composição diorítica até quartzo-monzonítica que ocupam cerca de 60\% do corpo exposto ao norte do Complexo Granítico de Lavras (Nardi, 1984). Com base nas variações texturais e composicionais, quatro fácies são reconhecidas no Monzonito Tapera: fácies plutônica monzonítica (fpm), fácies plutônica leucodiorítica (fpl), fácies plutônica diorítica (fpd) e fácies hipabissal monzonítica (fhm). As rochas plutônicas caracterizam-se pela expressiva variação textural em escala mesoscópica, são foliadas e possuem em geral margens resfriadas, marcadas pela ocorrência de termos porfiríticos, com aumento progressivo de matriz em direção às encaixantes. As rochas hipabissais têm composição monzonítica e são 
maciças, constituindo diques de direção EW a NW.

Todos os tipos litológicos do MT afloram preferencialmente na forma de matacões, raramente como lajeados. A foliação de fluxo tem grau de desenvolvimento variável e é marcada pelo alinhamento dimensional dos constituintes, principalmente de plagioclásio que, em raros locais, forma também lineação mineral. Apesar do reduzido número de medidas, resultante do tipo de afloramento, observa-se que a foliação tende a acompanhar os contornos do corpo intrusivo (Fig. 2C), com ângulo de mergulho médio a alto.

O Monzonito Tapera é intrusivo na Formação Maricá e no Complexo Metamórfico Arroio Marmeleiro gerando, sobre o último, metamorfismo de contato de fácies hornblenda cornubianito. A ocorrência de margens resfriadas do MT no contato com ambas as unidades sugere a formação de cornubianitos também sobre as litologias da Formação Maricá. Entretanto, não foram encontradas evidências neste sentido, o que pode ser devido também à escassez de afloramentos nesta região, razão pela qual o contato é inferido. Evidência adicional do contato intrusivo do MT é representada pela ocorrência de apófises diorítico-monzoníticas de espessura centimétrica nos cornubianitos do CMAM e por diques da fácies hipabissal monzonítica nas rochas da Formação Maricá.

$\mathrm{Na}$ fácies plutônica monzonítica predominam biotita-hornblenda monzonitos a quartzo-monzonitos, com monzodioritos subordinados, sendo típica a textura equigranular média a fina, com feldspatos sudédricos e minerais máficos euédricos, destacando-se anfibólio, biotita e restos de clinopiroxênio. Feições de acumulação de cristais são localizadas, e a ocorrência de enclaves microgranulares máficos centimétricos é comum.

A fácies plutônica leucodiorítica é caracterizada por clinopiroxênio-hornblenda-biotita leucodioritos a monzodioritos de textura equigranular média, localizadamente grossa, com plagioclásio ovoide. Feições cumuláticas são comuns, e mesocumulatos de plagioclásio e clinopiroxênio ocorrem de modo esporádico. A transição dos termos leucodioríticos para monzoníticos é marcada por composições monzodioríticas de textura heterogranular, onde os maiores cristais são de plagioclásio esverdeado. Enclaves máficos de dimensões centimétricas são abundantes.

A fácies plutônica diorítica é pouco expressiva na área mapeada, ocorrendo associada aos termos leucodioríticos. É constituída por enclaves e megaenclaves de clinopiroxênio-biotita-hornblenda dioritos com textura equigranular fina a microporfirítica, tendo esta última uma abundante matriz fanerítica fina a afanítica.

Na fácies hipabissal monzonítica ocorrem três tipos texturais distintos, em ordem decrescente de abundância: (i) biotita-hornblenda monzonitos porfiríticos, com fenocristais centimétricos e arredondados de K-feldspato acompanhados por plagioclásio, biotita e hornblenda, além de raros fenocristais milimétricos de clinopiroxênio. Xenocristais de quartzo são comuns, e a matriz é fanerítica fina a afanítica, compondo cerca de $85 \%$ do volume da rocha; (ii) biotita-hornblenda monzonitos porfiríticos com fenocristais centimétricos arredondados de K-feldspato acompanhados por plagioclásio, biotita e hornblenda, além de fenocristais milimétricos de quartzo, envolvidos por matriz feldspática fanerítica fina a afanítica que compõe cerca de $60 \%$ do volume da rocha; (iii) biotita monzonitos equigranulares finos a microporfiríticos, com fenocristais de K-feldspato, plagioclásio, piroxênio e hornblenda em matriz fanerítica muito fina.

\section{Formação Hilário (FH)}

O termo Hilário foi introduzido por Robertson (1966) para designar as rochas relacionadas a um extenso vulcanismo andesítico (derrames, tufos, brechas, conglomerados vulcânicos, fluxos de lama, grauvacas, diques, rochas máficas intrusivas e, de modo localizado, rochas dacíticas no topo da sequência), aflorantes principalmente entre a região da Mina Seival e o vale do Rio Camaquã, a leste de Lavras do Sul. Em 1978, Ribeiro e Fantinel formalizaram o termo Formação Hilário para designar as rochas de natureza vulcânica desta associação, com ampla distribuição na região de Lavras do Sul e, subordinadamente, em Caçapava do Sul, São Sepé, Vila Nova do Sul e Dom Pedrito. Segundo Lima \& Nardi (1998), na região de Lavras do Sul as rochas efusivas são representadas principalmente por traquibasaltos e traquiandesitos (shoshonitos) que são espacial e temporalmente associados a termos hipabissais monzoníticos, quartzo-monzoníticos e lamprofíricos, além de granitoides epizonais e leucodioritos cumuláticos, agrupados na Associação Shoshonítica de Lavras do Sul.

A Formação Hilário é representada, na área de estudo, por derrames andesíticos, concentrados na parte sudeste da mesma, e corpos hipabissais de andesitos e lamprófiros, principalmente diques de espessura métrica e orientação NE-SW, intrusivos na Formação Maricá, no Monzonito Tapera, nos Dioritos Arroio Branquilho e nos próprios derrames da FH.

As rochas que compõem os derrames andesíticos têm textura porfirítica e raramente traquítica, apresentando frequentemente autobrechação. Possuem fenocristais milimétricos subédricos a euédricos, sem orientação preferencial, de plagioclásio, anfibólio e/ ou piroxênio, envoltos por uma matriz originalmente vítrea a microcristalina, composta por plagioclásio e resíduo vítreo. Observa-se ampla variação modal da composição mineral e da razão matriz/fenocristais.

As rochas hipabissais, representadas por andesitos, ocorrem principalmente como diques e têm características semelhantes às dos derrames, com pequeno aumento na granulação da matriz. Lamprófiros espessartíticos são raros, formando diques de espessura métrica. Estas rochas são maciças e têm textura por- 
firítica, com matriz fina, à base de plagioclásio, e fenocristais milimétricos e euédricos de anfibólio, subordinadamente de piroxênio, sem orientação preferencial.

A unidade não apresenta feições deformacionais dúcteis, sendo afetada somente por falhas e fraturas subverticais de direção dominantemente NE e, subordinadamente, NW.

\section{Formação Cerro da Pedra (FCP)}

Na área de estudo, são mapeadas litologias conglomeráticas na forma de um corpo alongado, com cerca de $10 \mathrm{~km}$ de comprimento e $3 \mathrm{~km}$ de largura, limitado por falhas de direção NE que as colocam em contato com as rochas do embasamento. Estas litologias foram anteriormente definidas como parte da Série Camaquã (Carvalho, 1932), Formação Santa Bárbara (Robertson, 1966), Sequência Vulcanossedimentar IV (Leites et al., 1990) e Aloformação Santa Fé (Paim, 1995). Na área, a designação Formação Santa Fé foi empregada por Porcher (2000), em correlação à aloformação definida por Paim (1995), com posicionamento estratigráfico acima da Formação Acampamento Velho.

As evidências de campo obtidas durante a realização do Projeto Arroio América (UFRGS, 2003) contrariam as designações anteriores, uma vez que a frequência de intrusões riolíticas relacionadas à Formação Acampamento Velho nestas litologias sedimentares indica que elas são mais antigas. Clastos de andesitos da Formação Hilário são encontrados no arcabouço dos conglomerados, evidenciando seu posicionamento posterior ao evento vulcânico desta formação e anterior ao magmatismo da Formação Acampamento Velho. Propõe-se, portanto, a denominação de Formação Cerro da Pedra (localização da seção tipo no quadro 1), em alusão à feição topográfica que se encontra cerca de $500 \mathrm{~m}$ a nordeste da área mapeada.

A Formação Cerro da Pedra é constituída por duas fácies, composicional e estruturalmente distintas, descritas como fácies proximal, composta por para e ortoconglomerados oligomíticos, e fácies distal, composta por ortoconglomerados polimíticos, tendo sua gênese relacionada a sistemas de leques aluviais. Embora seus contatos sejam em grande parte tectônicos, evidências de campo indicam que esta unidade sobrepõe-se às rochas da Formação Maricá em discordância angular, e aos Dioritos Arroio Branquilho e Tonalito Arroio dos Carros em não-conformidade.

Os para e ortoconglomerados oligomíticos da fácies proximal constituem camadas lenticulares de espessura métrica, sem organização interna, contendo seixos e blocos de arenitos arcoseanos e traquitos, com clastos de granito subordinados.

Os ortoconglomerados polimíticos da fácies distal formam camadas lenticulares de espessura métrica, com estrutura interna em geral desorganizada e, subordinadamente, mostrando estratificação cruzada acanalada de médio a grande porte. Contêm seixos, blocos e matacões de arenitos correlacionáveis à Formação Maricá, granitos, quartzo leitoso, milonitos e rochas vulcânicas básicas a intermediárias. Subordinadamente intercalam-se lentes de até $50 \mathrm{~cm}$ de espessura de arenitos grossos, mal selecionados, com estratificação cruzada acanalada. De modo localizado, paleocorrentes indicam a existência de área-fonte a W-NW.

A unidade é afetada por uma zona de falha de direção NNE, com movimento transcorrente esquerdo evidenciado pela quebra e deslocamento de blocos do arcabouço dos ortoconglomerados polimíticos. As camadas encontram-se basculadas, com mergulho de até $50^{\circ}$ (Fig. 2D).

\section{Formação Acampamento Velho (FAV)}

A Formação Acampamento Velho é caracterizada como uma sequência vulcânica bimodal, com amplo predomínio de vulcanitos ácidos, sendo interpretada como a porção extrusiva do volumoso magmatismo alcalino sódico saturado em sílica relacionado aos estágios pós-colisionais do Ciclo Orogênico Brasiliano/Panafricano no Escudo Sul-rio-grandense (Wildner et al., 1999, Almeida et al., 2002, Sommer et al., 2005). Esta unidade reúne um grande volume de depósitos efusivos e piroclásticos de composição ácida associados a lavas e diques de composição básica, cujas melhores exposições estão localizadas no Platô da Ramada e no Cerro Tupanci (Vila Nova do Sul), Platô do Taquarembó (Dom Pedrito) e nos cerros do Bugio e do Perau (Caçapava do Sul).

Os primeiros registros sobre a FAV foram feitos na região do Platô da Ramada, no trabalho de Leinz et al. (1941), que descreveram riolitos extrusivos no "Planalto da Ramada" e os classificaram como quartzo-pórfiros. Robertson (1966) propôs a criação de uma nova unidade litoestratigráfica, na categoria de formação, denominada Riolito Ramada, que compreendia depósitos de tufos riolíticos, principalmente no Platô da Ramada e em cristas orientadas segundo a direção NE-SW, nas serras de Santa Bárbara e Santa Barbinha. Ribeiro et al. (1966) propuseram a formalização do Membro Acampamento Velho para a unidade litoestratigráfica que incluía riolitos, dacitos e piroclásticas associadas. A elevação de categoria desta unidade, de Membro para Formação, foi proposta por Cordani et al. (1974) e utilizada por Ribeiro \& Fantinel (1978). Dados geocronólogicos obtidos a partir de análises $\mathrm{U}-\mathrm{Pb}$ SHRIMP em zircões extraídos de riolitos resultaram em idades de 57318 Ma (Chemale Jr., 2000), na região do Passo do Salsinho, e $549 \pm 5$ Ma na região do Platô da Ramada (Sommer et al., 2005).

Esta unidade está representada na área de estudo por uma grande feição dômica de rochas riolíticas, denominada Cerro Formoso, que forma um alto topográfico com desnível aproximado de $200 \mathrm{~m}$. Localizado na porção norte da área, este corpo é alongado na direção NW-SE e possui aproximadamente $4 \mathrm{~km}$ de extensão, 
encaixado em lineamentos de direção NW-SE que o colocam em contato com os Dioritos Arroio Branquilho. A FAV é também representada por diques de riolito intrusivos na Formação Maricá, no Granito Passo da Chácara, nos Granitoides Rincão dos Encerrados, no Tonalito Arroio dos Carros e na Formação Cerro da Pedra, orientados preferencialmente na direção NE-SW.

Os riolitos são porfiríticos, com fenocristais euédricos de ortoclásio e quartzo de $0,5 \mathrm{~mm}$ em média, em matriz quartzo-feldspática abundante, fanerítica fina, por vezes com textura esferulítica.

\subsection{Grupo Itararé}

\section{Formação Rio do Sul (FRS)}

Para o Grupo Itararé, uma série de formações é mapeada no depocentro da Bacia do Paraná, notadamente no norte de Santa Catarina e sul do Paraná. No Rio Grande do Sul, contudo, ocorrem apenas os estratos mais superiores deste grupo, reunidos na chamada Formação Rio do Sul (Schneider et al., 1974; Aboarrage \& Lopes, 1986), possuindo espessuras de até $80 \mathrm{~m}$, fazendo contato discordante erosivo com as rochas do embasamento cristalino ou com as rochas sedimentares da Bacia do Camaquã.

Esta formação é composta por uma associação complexa de diamictitos, arenitos de granulação fina a média, siltitos pretos, varvitos e ritmitos com clastos pingados, representando fácies originadas em ambientes glacio-continentais e principalmente glacio-marinhos (turbiditos e fluxos de detritos coesivos originados a partir de leques subaquosos de outwash glacial).

A Formação Rio do Sul tem ocorrência restrita ao extremo norte da área mapeada, onde é representada por camadas de geometria tabular, com basculamento de aproximadamente $15^{\circ}$ para NE ou SW, em discordância angular com a Formação Maricá. Sua laminação é plano-paralela, mas a espessura das lâminas é variável. As litologias são medianamente litificadas, constituindo uma intercalação de camadas mais espessas e irregulares de arenito quartzo-feldspático de granulação fina com camadas de siltito. Em amostra fresca, têm coloração rosada. Quando alteradas, a coloração é amarelada e marrom-avermelhada, o que facilita a visualização da laminação plano-paralela.

\section{Considerações finais}

O mapeamento geológico efetuado na Folha Arroio América possibilitou reavaliar a importância em volume de diversas unidades litoestratigráficas, bem como a descrição e denominação de novas unidades, tanto nas sequências de embasamento quanto nas de cobertura.

A grande área previamente atribuída aos gnaisses do Complexo Cambaí mostrou-se consideravelmen- te reduzida, sendo nela reconhecido o predomínio de dioritos indeformados ou milonitizados e granitoides sintectônicos. As unidades dioríticas e tonalíticas identificadas nesta área guardam significativa semelhança composicional e estrutural com as da região de Vila Nova do Sul, a oeste, incluindo a evolução do magmatismo de diorítico para tonalítico e granítico.

No Monzonito Tapera, são reconhecidas e mapeadas diversas fácies composicionais e texturais, bem como o metamorfismo de contato provocado nos metamorfitos encaixantes, que atingiu a fácies hornblenda cornubianito.

As litologias conglomeráticas previamente atribuídas à Formação Santa Bárbara são redefinidas como Formação Cerro da Pedra e seu posicionamento estratigráfico estabelecido entre as Formações Hilário e Acampamento Velho, do Grupo Bom Jardim.

A Zona de Cisalhamento Arroio América é definida como uma estrutura transcorrente esquerda, com ao menos uma reativação importante em nível mais raso e mesmo sentido de movimento, acompanhado de componente oblíqua.

As reativações relacionadas à ZCAA, bem como as falhas de direção NW-SE e movimento lateral direito, também com componente oblíqua, são responsáveis pelo significativo basculamento dos pacotes sedimentares da Formação Maricá. Reativações ainda mais tardias destas estruturas são responsáveis pelo basculamento dos pacotes sedimentares da Formação Cerro da Pedra e, em menor escala, da Formação Rio do Sul (Grupo Itararé).

\section{Referências}

Aboarrage, A.M. \& Lopes, R.C. 1986. Projeto A Borda Leste da Bacia do Paraná: integração geológica e avaliação econômica. Porto Alegre: DNPM/CPRM. 18v. Relatório final. Inédito.

Almeida, D.P.M; Zerfass, H.;,Basei, M.A.S., Petry, K. \& Gomes, C.H. 2002. The Acampamento Velho Formation, a lower Cambrian bimodal volcanic package: Geochemical and Stratigraphic studies from the Cerro do Bugio, Perau and Serra de Santa Bárbara (Caçapava do Sul, Rio Grande do Sul, RS - Brazil). Gondwana Research, 5: 721-733.

Bitencourt, M.F., Nardi, L.V.S., Philipp, R.P. \& Garavaglia, L. 2004. Litoestratigrafia das Rochas Plutônicas: discussão de conceitos, critérios e terminologia. In: REUNIÃO ABERTA DA COMISSÃO BRASILEIRA DE ESTRATIGRAFIA, 2004, Porto Alegre. Anais... Porto Alegre, SBG, p.56-61.

Carvalho, P.F. 1932. Reconhecimento Geológico do Estado do Rio Grande do Sul. Boletim do Instituto Geológico e Mineiro do Brasil, 66: 1-72.

Chemale Jr., F. 2000. Evolução Geológica do Escudo Sul-rio-grandense. In: Holz, M. \& De Ros, L.F. (Ed.). 2000. Geologia do Rio Grande do Sul. Porto Alegre, Centro de Investigação do Gondwana, Instituto de Geociências, UFRGS, p.13-52.

Cordani, U.G., Halpern, M. \& Berenholc, M. 1974. Comentários sobre as Determinações Geocronológicas na Folha Porto Alegre. In: Carta geológica do Brasil ao Milionésimo, 
texto explicativo das folhas Porto Alegre e Lagoa Mirim. Brasília, DNPM, p. 70-84.

Fernandes, L.A.D. \& Porcher, C.C. 2000. Geologia Estrutural. In: Porcher; C.A. (Coord.). Programa Levantamentos Geológicos Básicos do Brasil, Folha SH.22-Y-A. Estado do Rio Grande do Sul. Brasília, CPRM. cap. 3, p. 59-92. Escala 1:250.000.

Gastal, M.C.P., Teixeira, W., Lafon, J.M. \& Remus, M.V.D. 2005. Geocronologia ${ }^{40} \mathrm{Ar} /{ }^{39} \mathrm{Ar},{ }^{207} \mathrm{~Pb} /{ }^{206} \mathrm{~Pb}$ e ${ }^{206} \mathrm{~Pb} /{ }^{238} \mathrm{U}$ do Complexo Intrusivo Lavras do Sul, RS. In: SIMPÓSIO SOBRE VULCANISMO E AMBIENTES ASSOCIADOS, 3., Cabo Frio, 2005. Anais... Rio de Janeiro, SBG. v. 1, p. 83-88.

Gastal, M.C.P., Lafon, J.M., Ferreira, F.J.F., Magro, F.U.S., Remus, M.V.D. \& Sommer, C.kraeA. 2006. Reinterpretação do Complexo Intrusivo Lavras do Sul, RS, de acordo com os sistemas vulcano-plutônicos de subsidência. Parte 1: geologia, geofísica e geocronologia $\left({ }^{207} \mathrm{~Pb} /{ }^{206} \mathrm{~Pb} \mathrm{e}{ }^{206} \mathrm{~Pb} /{ }^{238} \mathrm{U}\right)$. Revista Brasileira de Geociências, 36(1): 99-112.

International Subcommission on Stratigraphic Classification (ISSC) of IUGS. 1994. International Stratigraphic Guide B - a guide to stratigraphic classification, terminology and procedure. New York, John Wiley, 214p.

Kraemer, G. 1995. Evolução Magmática e Tectônica da Suíte Ortometamórfica Imbicuí, Região de l Lavras do Sul (RS). Porto Alegre. 99p. Dissertação de Mestrado em Geociências, Instituto de Geociências, Universidade Federal do Rio Grande do Sul.

Leinz, V., Barbosa, A.F. \& Teixeira, E.A. 1941. Mapa Geológico Caçapava-Lavras. Boletim da Secretaria Estadual de Agricultura, Indústria e Comércio, 90:1-39.

Leites, S.R.; Lopes, R.C.; Wildner, W.; Porcher, C.A. \& Sander, A. 1990. Divisão litofaciológica da Bacia do Camaquã na Folha Passo do Salsinho, Caçapava do Sul - RS, e sua interpretação paleoambiental. In: CONGRESSO BRASILEIRO DE GEOLOGIA, 36., 1990, Natal. Anais... Natal, SBG, v.1, p. 300-312.

Lima, E.F. \& Nardi, L.V.S. 1992. O magmatismo shoshonítico no estado do Rio Grande do Sul. Uma revisão. Pesquisas, 19: 190-194.

Lima, E.F. \& Nardi, L.V.S. 1998. The Lavras do Sul Shoshonitic Association: implications for the origin and evolution of Neoproterozoic shoshonitic magmatism in southernmost Brazil. Journal of South American of Earth Sciences, 11(1): 67-77.

Matos Neto, J.B., De Ros, L.F. \& Ferrari, M. 1980. Projeto FoIha de Lavras do Sul-RS. Geologia da Faixa I. Porto Alegre. 349p. Trabalho de Graduação, Curso de Graduação em Geologia, Instituto de Geociências, Universidade Federal do Rio Grande do Sul.

Nardi, L.V.S. 1984. Geochemistry and petrology of the Lavras do Sul Granite Complex, RS, Brazil. Londres. 268p. PhD Thesis, Department of Geology, King's College, University of London.

Nardi, L.V.S. \& Bonin, B. 1991. Post-orogenic and non-orogenic alkaline granite associations: the Saibro Intrusive Suite, Southern Brasil: a case study. Chemical Geology, 92: 197-211.

Nardi, L.V.S. \& Lima, E.F. 1985. A Associação Shoshonítica de Lavras do Sul. Revista Brasileira de Geociências, 15: 139146.

Paim, P.S.G. 1994. Depositional Systems and Palaeogeographical Evolution of the Camaquã and Santa Bárbara Basins, Brazil. Oxford. 277p. PhD Thesis, University of Oxford.

Paim, P.S.G. 1995. Alluvial palaeogeography of the Guaritas depositional sequence of southern Brazil. Special Publication of the International Association of Sedimentologists, 22: 3-16.

Paim, P.S.G.; Chemale Jr., F. \& Lopes, R.C. 1995. Aloestratigrafia, sistemas deposicionais e evolução paleogeográfica da Bacia do Camaquã - Vendiano superior/Ordoviciano inferior do RS. In: SIMPÓSIO SUL-BRASILEIRO DE GEOLOGIA, 6., 1995, Porto Alegre. Boletim... Porto Alegre, SBG, p. 39-50.

Paim, P.S.G., Chemale Jr., F. \& Lopes, R.C. 2000. A Bacia do Camaquã. In: Holz, M. \& De Ros, L.F. (ed.). 2000. Geologia do Rio Grande do Sul. Porto Alegre, Centro de Investigação do Gondwana, Instituto de Geociências, UFRGS, p. 231-274.

Philipp, R.P., Nardi, L.V.S. \& Bitencourt, M.F. 2003. Estratigrafia das Rochas Plutônicas: revisão e comentários. In: ENCONTRO SOBRE ESTRATIGRAFIA DO RIO GRANDE DO SUL: ESCUDO E BACIAS, 1., 2003, Porto Alegre. Anais... Porto Alegre, SBG, p. 95-98.

Porcher, C.A. (Coord.). 2000. Programa Levantamentos Geológicos Básicos do Brasil, Folha Cachoeira SH.22-Y-A. Estado do Rio Grande do Sul. Brasília, CPRM. 131p. Escala $1: 250.000$.

Ribeiro, M. 1983. Informes sobre a Formação Maricá. Iheringia, Série Geologia, 7: 1-50.

Ribeiro, M., Bocchi, P.R., Figueiredo Filho, P.M. \& Tessari, R.I. 1966. Geologia da Quadrícula de Caçapava do Sul, Rio Grande do Sul, Brasil. Boletim da Divisão de Fomento Mineral e Produção, Rio de Janeiro, 127: 1-232. 1 mapa. Escala $1: 250.000$.

Ribeiro, M. \& Fantinel, L.M. 1978. Associações petrotectônicas do Escudo Sul-Riograndense: I. Tabulação e distribuição das Associações Petrotectônicas do Escudo do Rio Grande do Sul. Iheringia, Série Geologia, 5: 19-54.

Robertson, J.F. 1966. Revision of the stratigraphy and nomenclature of rock units in the Caçapava-Lavras region, State of Rio Grande do Sul, Brasil. Notas e Estudos, 1: 41-54.

Schneider, R.L., Mühlmann, H., Tommasi, E., Medeiros, R.A., Daemon, R.F. \& Nogueira, A.A. 1974. Revisão estratigráfica da Bacia do Paraná. In: CONGRESSO BRASILEIRO DE GEOLOGIA, 28., 1974, Porto Alegre. Anais... Porto Alegre, SBG, v.1, p. 41-66.

Sommer, C.A., Lima, E.F., Nardi, L.V.S., Figueiredo, A.M.G. \& Pierosan, R. 2005. Potassic and low- and high-Ti mildly alkaline volcanism in the Neoproterozoic Ramada Plateau, southermost Brazil. Journal of South American Earth Sciences, 18(3): 237-254.

UFRGS. Universidade Federal do Rio Grande do Sul. 1997. Mapeamento Geológico 1:25.000 da Folha Vila Nova (MI2982/3) e Parte da Folha Passo do Salsinho (MI2982/4), $R S$. Porto Alegre. 8 vol., 2 mapas. Trabalho de Graduação do Curso de Geologia, Instituto de Geociências, Universidade Federal do Rio Grande do Sul.

UFRGS. Universidade Federal do Rio Grande do Sul. 2001. Mapeamento Geológico 1:25.000 de Parte das Folhas Vila Nova (MI2982/3) e Rufino Farias (MI2981/4), RS. Porto Alegre. 1 vol., 2 mapas. Mapeamento Geológico Básico. Curso de Graduação em Geologia, Instituto de Geociências, Universidade Federal do Rio Grande do Sul.

UFRGS. Universidade Federal do Rio Grande do Sul. 2003. Mapeamento Geológico 1:25.000 de Parte da Folha Arroio América (MI2995/1), RS. Porto Alegre. 1 vol., 2 mapas. Mapeamento Geológico Básico. Curso de Graduação em Geologia, Instituto de Geociências, Universidade Federal do Rio Grande do Sul. 
White, A.J.R., Allen, C.M., Beams, D., Carr, P.F.; Champion, D.C., Chappell, B.W., Wyborn, D. \& Wyborn, L.A.I. 2001. Granite Suites and Supersuites of Eastern Australia. Australian Journal of Earth Sciences, 48: 515-530.

Wildner, W., Nardi, L.V.S. \& Lima, E.F. 1999. Post-collisional

Manuscrito 356

Editor: Paulo A. de Souza.
Alkaline Magmatism on the Taquarembó Plateau: a well Preserved Neoproterozoic-Cambrian Plutono-volcanic Association in Southern Brazil. International Geology Review, 41: 1082-1098. 